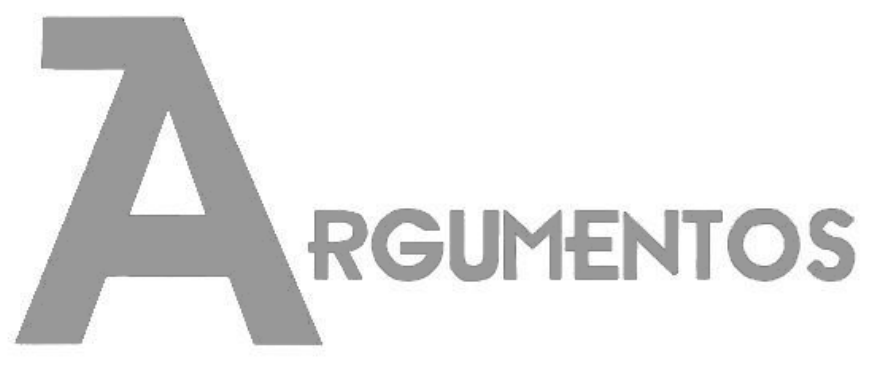

Vol. 17, n. 1, jan./jun. 2020 ISSN: 2527-2551 (online)

https://www.periodicos.unimontes.br/index.php/argumentos

\title{
Política econômica no Pachamamismo do Buen Vivir: um estudo teórico
}

\author{
Isaías Albertin de Moraes ${ }^{1}$ \\ Leandro Pereira Morais ${ }^{2}$
}

Recebido em: 25/06/2019

Aprovado em: 06/12/2019

Resumo: O presente artigo tem como objetivo investigar o Pachamamismo (denominação dada a corrente Indigenista-Pachamamista presente nos preceitos teóricos do Buen Vivir). A pergunta levantada pela pesquisa é: há uma proposta de política econômica própria do Pachamamismo? Para responder à pergunta elencada, o artigo utilizou-se da metodologia descritiva-qualitativa e como procedimento técnico uma abordagem sistemática por meio da avaliação crítica dos dados bibliográficos e documentais sobre a temática. Na primeira parte do texto, apresentou-se o conceito de Buen Vivir. Na segunda parte da pesquisa, aprofundou-se no campo semântico do conceito de Pachamamismo, evidenciando sua densidade histórica, estrutura social e investigando se os autores da corrente apresentam uma política econômica originalmente Indigenista-Pachamamista. Os resultados apontam que o Pachamamismo tem uma estrutura filosófica e antropológica bem estruturada. No entanto, o Pachamamismo carece de uma política econômica própria e original.

Palavras-chave: Buen Vivir; Pachamamismo; Desenvolvimento Econômico; Filosofia andina; História da América Latina.

\section{Política económica en el Pachamamismo del Buen Vivir: un estudio teórico}

Resumen: Este artículo tiene como objetivo investigar el Pachamamismo (denominación dada a la corriente indígena-Pachamamista presente en los preceptos teóricos del Buen Vivir). La pregunta que plantea la encuesta es: ¿Existe una propuesta de política económica del Pachamamismo? Para contestar a la pregunta, el artículo utilizó la metodología descriptivacualitativa y, como procedimiento técnico, un enfoque sistemático a través de la evaluación

\footnotetext{
1 Pesquisador do Núcleo de Extensão e Pesquisa em Economia Solidária, Criativa e Cidadania (NEPESC/Unesp). Doutorando em Ciências Sociais pela Unesp/Araraquara. Bolsista da Coordenação de Aperfeiçoamento de Pessoal de Nível Superior (CAPES). E-mail: isaias.a.moraes@unesp.br. ORCID: http://orcid.org/0000-0003-1839-803X.

2 Professor do Departamento de Economia da Unesp/Araraquara. Coordenador do NEPESC/Unesp. Doutorado em Desenvolvimento Econômico (Economia Social e do Trabalho) pela Universidade Estadual de Campinas (UNICAMP). E-mail: leandro.morais@unesp.br. ORCID: http://orcid.org/0000-0002-39459455.
} 
crítica de datos bibliográficos y documentales sobre el tema. En la primera parte del texto, se presentó el concepto de Buen Vivir. En la segunda parte de la investigación, se profundizó en el campo semántico del concepto de Pachamamismo, evidenciando su densidad histórica, estructura social e investigando si los autores de la corriente presentan una política económica originalmente indigenista-pachamamista. Los resultados muestran que el Pachamamismo tiene una estructura filosófica y antropológica bien estructurada. Sin embargo, el pachamamismo carece de su propia política económica original.

Palabras-clave: Buen Vivir; Pachamamismo; Desarrollo económico; Filosofía andina; Historia de Latinoamérica

\section{Economic policy in the Pachamamismo of the Buen Vivir: a theoretical study}

Abstract: This article aims to investigate Pachamamismo (denomination given to the IndigenistPachamamista current present in the theoretical precepts of Buen Vivir). The question raised by the research is: is there a proposal for economic policy proper to Pachamamismo? To answer the question, the article used the descriptive-qualitative methodology and as a technical procedure a systematic approach through the critical evaluation of bibliographic and documentary data on the theme. The work is divided into two parts. In the first part of the text, the concept of Buen Vivir was presented. In the second part of the research, it was deepened in the semantic field of the concept of Pachamamismo, evidencing its historical density, social structure and investigating whether the authors of the current present an economic policy originally Indigenist- Pachamamista. The results indicate that Pachamamismo has a wellstructured philosophical and anthropological structure. However, Pachamamismo lacks its own original economic policy.

Keywords: Buen Vivir; Pachamamismo; Economic development; Andean philosophy; History of Latin America.

\section{Introdução}

O continente latino-americano teve o primeiro país como "laboratório" dos preceitos neoliberais na década de 1970, o Chile. A materialização do projeto neoliberal ocorreu no Chile após o golpe de estado promovido pelo General Augusto Pinochet com apoio dos Estados Unidos da América (EUA) contra o governo democrático do socialista Salvador Allende (1970 - 1973). De 1973 a 1990, o regime ditatorial de Pinochet colocou em prática o receituário neoliberal como: controle da emissão monetária, aumento da taxa de juros, flexibilização das leis trabalhistas, privatização dos bens e serviços estatais, além da promoção dos valores individuais, comerciais, financeiros e competitivos. O Ladrilho, plano de ação econômico desenvolvido pelo governo de Pinochet, contou com apoio direto do economista neoliberal Milton Friedman, do economista da escola austríaca ultraliberal Friedrich Hayek, além do economista neoliberal chileno Jorge Cauas (CASTELO, 2013; KATZ, 2016). 
Artigo | Política econômica no Pachamamismo do Buen Vivir: um estudo teórico (MORAES, Isaías Albertin de; MORAIS, Leandro Pereira)

Desde a experiência chilena durante o regime ditatorial de Pinochet com apoio dos EUA, os países latino-americanos se converteram em um grande "laboratório" das políticas econômicas neoliberais. Inicialmente, a intensidade das experiências neoliberais foi relativa em cada país da região de acordo com seus arranjos políticos, sociais e econômicos. Contudo, na década de 1980, com a crise do modelo nacionaldesenvolvimentista vigente em grande parte das economias da região, incluindo as maiores - Brasil, Argentina e México -, o neoliberalismo avançou (HARVEY, 2008; MARTINS, 2011).

As nações latino-americanas com seu modelo nacional-desenvolvimentista, que na ocasião estava sendo financiando via capital externo, tornaram-se insolventes na década de 1980. Suas dívidas acentuaram drasticamente, os países da região não conseguiram mais captar recursos internacionais por falta de liquidez e não possuíam reservas para arcar com seus compromissos externos. A situação resultante foi uma espiral de inflação, endividamento externo e estagnação econômica para esses países. Inflação galopante, desequilíbrios nas contas públicas, desemprego e falta de legitimidade política foram minando o apoio social-político que o nacionaldesenvolvimentismo ainda possuía na América Latina. Tal cenário permitiu que as experiências neoliberais no "laboratório América Latina" se intensificassem na década de 1990 com as diretrizes do Consenso de Washington.

De acordo com Katz (2016), o neoliberalismo latino-americano atravessou duas etapas diferenciadas. Em uma primeira fase prevaleceram às reformas de cunho monetaristas e fiscais com prioridade para conter a hiperinflação. Em um segundo momento aprofundaram-se as reformas neoliberais, a abertura comercial, as privatizações e a flexibilização do trabalho. Os objetivos eram conseguir equilíbrio macroeconômico, melhorar a eficiência ao restaurar padrões de risco, de esforço e de produtividade, aumentando, a empregabilidade e o dinamismo da economia, logo o crescimento dos rendimentos populares e a diminuição da desigualdade.

Embora algumas medidas neoliberais tenham obtido êxito em controlar a inflação, adotando uma consistência macroeconômica como: sistema de metas de inflação e superávit primário; e embora os governos da América Latina tenham executados importantes reformas estruturais, diminuindo expressivamente o papel do Estado na economia, a região não conseguiu apresentar um bom desempenho em 
Artigo | Política econômica no Pachamamismo do Buen Vivir: um estudo teórico (MORAES, Isaías Albertin de; MORAIS, Leandro Pereira)

termos de desenvolvimento econômico e diminuição da desigualdade social. A ortodoxia convencional não entregou o prometido.

No fim da década de 1990, o forte caráter monetarista de operacionalizar a economia de uma nação presente no neoliberalismo teve como resultado, particularmente, o controle inflacionário nas economias da América Latina. Entretanto, por outro lado, ocorreu, nos países latino-americanos, a consolidação do mito e do fetiche da supressão do trabalho vivo em consequência do deslocamento do mercado das atividades produtivas e do simbolismo da fábrica, como elemento de produção, para o mercado financeiro e os bancos comerciais e não comerciais. O capitalista produtivista perdeu centralidade das atividades de gerenciamento de acumulação de capital para os setores financeiros e para o capitalista rentista com seus complexos fluxos de capitais em nível global. O trabalhador sindicalizado cedeu espaço para o precariado em sentido lato e na "pejotização", isto é, o autônomo exclusivo sem vínculo empregatício.

No final do século XX e início do século XXI, a força motriz das relações sociais capitalistas na América Latina tornou-se centrada no mercado financeiro em parceria com o capitalista rentista, orbitando em setores de serviços que, não raramente, são reféns de uma acumulação pautada essencialmente na superexploração da força do trabalho. Em diversos países da região houve redução dos direitos sociais, aumento do desemprego estrutural, da desigualdade social, fazendo com que houvesse diversas manifestações populares para frearem a ofensiva neoliberal. O modelo ideopolítica do neoliberalismo foi questionado (MARTINS, 2011; BRESSER-PEREIRA, 2018; DOWBOR, 2017).

A descrença na ortodoxia convencional em determinados países da América Latina e a crise do capitalismo mundial em 2008 permitiram com que novas propostas teóricas com suas correntes se aflorassem na região. Nos primeiros anos do século XXI, a América Latina produziu e experimentou uma profusão de novas ideias e de teorias acerca de como almejar o desenvolvimento econômico e o bem-estar social. As principais correntes que "rodaram" nos principais países do "laboratório" América Latina foram: Buen Vivir (Bolívia e Equador), Socialismo do Século XXI (Venezuela e Nicarágua) e Social Desenvolvimentismo (Brasil, Argentina e Uruguai), outras economias importantes da região orbitaram entre o Social liberalismo e o Neoliberalismo, com exceção de Cuba que adotou uma Renovação Socialista. Os governos de Fernando Lugo 
Artigo | Política econômica no Pachamamismo do Buen Vivir: um estudo teórico (MORAES, Isaías Albertin de; MORAIS, Leandro Pereira)

no Paraguai e de José Manuel Zelaya em Honduras não tiveram tempo de colocar seus projetos em curso, logo não sendo possível categorizá-los.

É diante dessa densidade histórica, conjuntura político-econômica e estrutura social que o presente artigo se encarrega de focar na corrente do Buen Vivir intitulada de Pachamamismo. A escolha de analisar o pensamento Indigenista-Pachamamista do Buen Vivir, concentrando-se na sua proposta de política econômica, deve-se em virtude da escassez de material produzido sobre a temática, especialmente em português. A pergunta levantada pela pesquisa é: há uma proposta de política econômica no Pachamamismo? A hipótese é de que o Pachamamismo não possui um arcabouço de política econômica original e própria, permanecendo no âmbito do culturalismo e da filosofia social.

Para procurar responder à pergunta proposta e testar a hipótese elencada, o artigo se dividiu em duas partes. Na primeira parte do texto, apresentou-se o conceito de Buen Vivir. Na segunda parte da pesquisa, aprofundou-se no campo semântico do conceito de Pachamamismo, investigando se há uma política econômica original Indigenista-Pachamamista, como há, por exemplo, novas contribuições econômicas no pensamento desenvolvimentista e socialista.

O artigo utilizou-se da metodologia descritiva-qualitativa e priorizou como procedimentos técnicos uma abordagem sistemática por meio da avaliação crítica dos dados bibliográficos e documentais. A avaliação crítica e sistemática dos dados bibliográficos e documentais iniciou-se em 2017 durante aperfeiçoamento em Economias Latino-americanas pela Comissão Econômica para a América Latina e o Caribe das Nações Unidas (CEPAL/ONU) realizada pelo autor. Em 2019, a avaliação crítica de dados bibliográficos se consolidou por novas leituras, palestras e debates realizados no âmbito do Comité Académico Procesos Asociativos y Colaborativos (PROCOAS) de la Asociación de Universidades Grupo Montevideo (AUGM) e junto al Área Sector Cooperativo y de Economía Social y Solidaria de Universidad de la República (UdelaR) no Uruguai, também pelo autor. Por fim, os fichamentos de fontes bibliográficas e documentais foram debatidos com outros pesquisadores, essencialmente com o coautor, do Núcleo de Extensão e Pesquisa em Economia Solidária, Criativa e Cidadania da Unesp (NEPESC/Unesp), assegurando, assim, a produção e consolidação do pensamento que se apresenta neste artigo. 
Artigo | Política econômica no Pachamamismo do Buen Vivir: um estudo teórico (MORAES, Isaías Albertin de; MORAIS, Leandro Pereira)

\section{Buen Vivir: uma proposta latino-americana}

Buen Vivir é uma expressão e filosofia de vida de difícil tradução presente nos principais idiomas dos povos originais da América Latina. O termo está nos idiomas: Kichwa (Sumak Kawsay), no Aymara (Suma Qamaña), no Guarani (Teko Porã, Teko Kavi ou Ñandereko), no Ashuar (Waras Shiir), no Awajún (Shin Pujut), no Mapuche (Küme Mongen), no Quiché (Utz Kaslemal) e no Tseltal (Lekil Kuxlejal). A maioria da literatura sobre Buen Vivir, Estermann, (2013); Jimézez, (2011); Mamani, (2010); Hidalgo-Capitán, (2012), traduz o termo como "vida boa" ou "vida plena" em comunidade e em harmonia com a natureza. O conceito, segundo Escobar (2011), fundamenta-se nas noções de cosmovisão relacional e pluriverso dos povos originários de Abya Yala (Terra madura, Terra Viva ou Terra em florescimento - autodesignação do povo Kuna para o território que eles habitam e que hoje é considerada América).

O Buen Vivir ganhou força como movimento político no final dos anos $1990 \mathrm{com}$ a crise do modelo neoliberal e do modelo nacional-desenvolvimentista na América Latina. Segundo Vanhulst e Beling (2014), os principais atores do Buen Vivir, inicialmente, foram os movimentos sociais dos povos originários, os movimentos anti/alter-globalização e os movimentos ambientalistas da América Latina, especialmente da região Andina. Não é por acaso que no início do século XXI, os primeiros autores a usarem a expressão Sumak Kawsay e Suma Qamaña foram intelectuais kichwas e aymaras como: Torrez (2001), Yampara (2001), Medina (2001) e Gualinga (2002).

Desde então, o conceito de Buen Vivir tem sido apresentado como: filosofia de vida (ACOSTA, 2010), cosmologia (WALSH, 2010), atitude de vida (CORTEZ 2011), ontologia (THOMSON, 2011), modelo de desenvolvimento (RADCLIFFE, 2012), alternativa ao desenvolvimento (GUDYNAS, 2011) e bioigualitarismo republicano (GALLEGOS, 2010). Uma coisa é unanimidade na literatura especializada, o Buen Vivir é uma visão de mundo diferenciada da ordem internacional liberal institucionalizada e do próprio desenvolvimento econômico nacional tradicional. Segundo Acosta: 
O Bem Viver deve ser considerado parte de uma longa busca de alternativas de vida forjadas no calor das lutas populares, particularmente dos povos e nacionalidades indígenas. São ideias surgidas de grupos tradicionalmente marginalizados, excluídos, explorados e até mesmo dizimados. São propostas invisibilizadas por muito tempo, que agora convidam a romper radicalmente com conceitos assumidos como indiscutíveis. Estas visões pósdesenvolvimentistas superam as correntes heterodoxas, que na realidade miravam a 'desenvolvimentos alternativos', quando é cada vez mais necessário criar 'alternativas ao desenvolvimento'. É disso que se trata o Bem Viver (ACOSTA, 2016, p. 70).

Como movimento político e teórico o Buen Vivir possui significativa presença na Bolívia, no Equador, na Colômbia, na Nicarágua, na Venezuela, no Panamá, na Guiana, no Peru, em Honduras e no México. León (2008) e Choquehuanca (2010) demonstram que o Buen Vivir busca recuperar a cultura da vida em harmonia com a natureza presente nos povos originais da região. No Buen Vivir todos os seres vivos são parte do todo. A Natureza, portanto, para o Buen Vivir, é um sujeito de direito, de modo igual ao ser humano. Os preceitos do Buen Vivir foram adotados na Constituição do Equador em 2008 (Capítulo segundo: Derechos del buen vivir) e na Constituição da Bolívia em 2009. As reformas constitucionais realizadas nesses dois países podem ser consideradas marco simbólico e concreto de uma proposta Buen Vivir e uma alternativa ao mainstream liberal.

A Constituição do Equador aponta claramente para os direitos da Pachamama (Capítulo sétimo: Derechos de la naturaleza) ao afirmar o Sumak Kawsay como direitos do bem-viver. Segundo a Constituição do Equador de 2008:

Decidimos construir una nueva forma de convivencia ciudadana, en diversidad y armonía con la naturaleza, para alcanzar el buen vivir, el sumak kawsay; una sociedad que respeta, en todas sus dimensiones, la dignidad de las personas y las colectividades (PERÁMBULO DA CONSTITUCIÓN DEL ECUADOR, 2008).

Art. 14.- Se reconoce el derecho de la población a vivir en un ambiente sano y ecológicamente equilibrado, que garantice la sostenibilidad y el buen vivir, sumak kawsay. Se declara de interés público la preservación del ambiente, la conservación de los ecosistemas, la biodiversidad y la integridad del patrimonio genético del país, la prevención del daño ambiental y la recuperación de los espacios naturales degradados. 
Artigo | Política econômica no Pachamamismo do Buen Vivir: um estudo teórico (MORAES, Isaías Albertin de; MORAIS, Leandro Pereira)

Art. 71.- La naturaleza o Pacha Mama, donde se reproduce y realiza la vida, tiene derecho a que se respete integralmente su existencia y el mantenimiento y regeneración de sus ciclos vitales, estructura, funciones y procesos evolutivos. Toda persona, comunidad, pueblo o nacionalidad podrá exigir a la autoridad pública el cumplimiento de los derechos de la naturaleza. Para aplicar e interpretar estos derechos se observaran los princípios establecidos en la Constitución, en lo que proceda. El Estado incentivará a las personas naturales y jurídicas, y a los colectivos, para que protejan la naturaleza, y promoverá el respeto a todos los elementos que forman un ecosistema.

Art. 72.- La naturaleza tiene derecho a la restauración. Esta restauración será independiente de la obligación que tienen el Estado y las personas naturales o jurídicas de Indemnizar a los individuos y colectivos que dependan de los sistemas naturales afectados. En los casos de impacto ambiental grave o permanente, incluidos los ocasionados por la explotación de los recursos naturales no renovables, el Estado establecerá los mecanismos más eficaces para alcanzar la restauración, y adoptará las medidas adecuadas para eliminar o mitigar las consecuencias ambientales nocivas.

Art. 73.- El Estado aplicará medidas de precaución y restricción para las actividades que puedan conducir a la extinción de especies, la destrucción de ecosistemas o la alteración permanente de los ciclos naturales. Se prohíbe la introducción de organismos y material orgánico e inorgânico que puedan alterar de manera definitiva el patrimonio genético nacional.

Art. 74.- Las personas, comunidades, pueblos y nacionalidades tendrán derecho a beneficiarse del ambiente y de las riquezas naturales que les permitan el buen vivir. Los servicios ambientales no serán susceptibles de apropiación; su producción, prestación, uso y aprovechamiento serán regulados por el Estado (CONSTITUCIÓN DEL ECUADOR, 2008).

De acordo com Maliska e Moreira (2017), o fato da natureza ser um sujeito de direito dentro do Buen Vivir é algo revolucionário, inovador e que rompe com a perspectiva antropocêntrica e se aproxima de uma cosmovisão de caráter fisiocêntrico com respeito ao pluralismo, inclusive jurídico, e ao multiculturalismo. O Buen Vivir, para Maliska e Moreira (2017), dessa forma, fortalece a democracia da região ao legitimar outras normativas e práticas comunitárias distintas da visão eurocêntrica colonialista. Para Acosta (2015), o Buen Vivir permite um repensar do Estado-nacional, recriando-o 
Artigo | Política econômica no Pachamamismo do Buen Vivir: um estudo teórico (MORAES, Isaías Albertin de; MORAIS, Leandro Pereira)

em uma forma plurinacional ao incorporar os códigos culturais e as nacionalidades dos povos originários e de outras comunidades marginalizadas da América Latina.

Para Boff (2014), o Buen Vivir propõe a construção de uma nova ética. Essa seria pautada no comunitarismo, no biocentrismo, na solidariedade e na cosmovisão. O Buen Vivir rejeita, assim, o paradigma dominante do capitalismo, seja em sua versão do neoliberalismo ou do nacional-desenvolvimentismo, porquanto para o Buen Vivir ambas escolas econômicas pregam valores ocidentais capitalistas como: meritocracia, individualismo, acumulação de riqueza, competição, produtivismo, dominação, exploração, subjugação; introjetando no homem o desejo de eliminação do outro e da própria natureza.

Segundo Mamani (2010), a estruturação do Buen Vivir leva em consideração uma renovação da estrutura educacional, passando por uma emancipação epistemológica que liberte o homem da racionalidade ocidental dominante e opressora. Para Mignolo (2005), o Buen Vivir pode ser interpretado como manifestação de descolonização epistêmica, isto é, um pensamento que desconstrói e abre possibilidades além das visões colonizadas pela racionalidade moderna imperialista eurocêntrica. A Constituição da Bolívia de 2009 afirma:

Artículo 8.

I. El Estado asume y promueve como principios ético-morales de la sociedad plural: ama qhilla, ama llulla, ama suwa (no seas flojo, no seas mentiroso ni seas ladrón), suma qamaña (vivir bien), ñandereko (vida armoniosa), teko kavi (vida buena), ivi maraei (tierra sin mal) y qhapaj ñan (camino o vida noble).

II. El Estado se sustenta en los valores de unidad, igualdad, inclusión, dignidad, libertad, solidaridad, reciprocidad, respeto, complementariedad, armonía, transparencia, equilibrio, igualdad de oportunidades, equidad social y de género en la participación, bienestar común, responsabilidad, justicia social, distribución y redistribución de los productos y bienes sociales, para vivir bien.

Artículo 30.

I. Es nación y pueblo indígena originario campesino toda la colectividad humana que comparta identidad cultural, idioma, tradición histórica, 
Artigo | Política econômica no Pachamamismo do Buen Vivir: um estudo teórico (MORAES, Isaías Albertin de; MORAIS, Leandro Pereira)

instituciones, territorialidad y cosmovisión, cuya existencia es anterior a la invasión colonial española (CONSTITUCIÓN POLÍTICA DEL ESTADO - CPE, BOLÍVIA, 2009).

Segundo Hidalgo-Capitán (2012), o Buen Vivir possui três correntes de pensamento: (1) Indigenista-Pachamamista, (2) Socialista-Estadista e (3) Pósdesenvolvimentista-ecologista. Todas as correntes possuem elaboração e discussão tanto nos movimentos sociais e políticos quanto na esfera acadêmica-teórica. A primeira corrente, segundo o autor, pode ser caracterizada pela relevância da autodeterminação dos povos originários de Abya Yalae (hoje América) no enaltecer dos aspectos prémodernos e mágico-espirituais (Pachamamismo) desses povos para a construção do Buen Vivir. A segunda vertente é representada pelos marxistas, sindicalistas e no enfoque que esses dão ao papel do Estado como motor político-econômico para o Buen Vivir. A terceira perspectiva corresponde aos ecologistas, feministas, teólogos, socialistas não marxistas e outros aportes indigenistas que apregoam um cooperativismo, comunitarismo e associativismo para estruturação do Buen Vivir.

A próxima seção se dedicará em apresentar a corrente IndigenistaPachamamista do Buen Vivir, tentando analisar se ela possui uma política econômica original. Em futuros estudos o autor se dedicará em explorar as demais correntes.

\section{A corrente indigenista-pachamamista do Buen-Vivir: Pachamamismo}

Compreender a formação de conceitos que permitam estudar a natureza e os fenômenos de determinado período histórico, neste caso o movimento do Pachamamismo no Buen Vivir, não é uma tarefa fácil. Para operacionalizar satisfatoriamente o abrangente significado de Pachamamismo faz-se necessário compreender primeiramente sua arqueologia e posteriormente sua construção teórica dentro do Buen Vivir.

O termo Pacha está na centralidade da cultura e da filosofia dos povos originários da região Andina. Em virtude de sua natureza polissêmica, contudo, Pacha tem significado extremamente abrangente, logo custoso de se operacionalizar em razão de sua amplitude conceitual. As traduções e definições de Pacha, não raramente, de acordo com Harris e Bouysse-Cassagne (1988), são precárias e limitadoras, uma vez que para os 
Artigo | Política econômica no Pachamamismo do Buen Vivir: um estudo teórico (MORAES, Isaías Albertin de; MORAIS, Leandro Pereira)

povos andinos o termo envolve sensações e sentimentos, algo mais abstrato do que concreto.

Segundo Estermann (1998, p. 47), Pacha “[...] é uma expressão para além da bifurcação visível e invisível, material e imaterial, [...] exterior ou interior. Se aproxima da ideia de um cosmo inter-relacionado, contendo tanto a temporalidade como espacialidade". Para Anjos e Fehlauer (2017), Pacha projeta uma totalidade préexistente que gera um movimento espaço-temporal e energético do mundo. Lajo (2006) define esse movimento de fluxos de tempo em que há uma coexistência do passado e do futuro, enquanto o presente é uma passagem fluida que permeia todos os seres em diferentes níveis de existência. Para Guillemot (2006, p. 55), Pacha pode ser entendido como o "universo vivo" composto por deuses e homens, "sustentação da vida" e "cosmos vivo inter-relacionado".

O sufixo Mama, por sua vez, representa o sagrado feminino, a mãe (GUILLEMOT, 2006). Isso faz com que a operacionalização do conceito de Pachamama seja usualmente realizada como "Mãe Terra". Entretanto, como salienta Anjos e Fehlauer (2017, p.111), Pachamama seria algo mais amplo, seria: "amor [...] pelo movimento da vida que vai da mãe para o filho". O foco da expressão, portanto, está na relacionalidade do movimento materno do universo vivo aos seus frutos e riquezas (incluindo nós) e não no ser ou ter. A centralidade é no movimento da vida, com sua fortuna e magnificência, e como isso ocorre sem nosso entendimento em um cosmo inter-relacionado. Quem faz esse movimento é a Pachamama, espaço-tempo feminino, após conjunção com trocas de fluxos coexistentes e complementares com Pachatata ${ }^{3}$ (Pai Terra), espaço-tempo masculino.

A corrente Indigenista-Pachamamista do Buen Vivir, usualmente intitulada de Pachamamismo, resguarda o olhar e valoriza esse movimento responsável de fornecer a sustentação da vida e o inter-relacionamento dos seres, do cosmo e seus orbes. Desse modo, resgata a filosofia e a cosmovisão andina e suas práxis social, apresentando-se como defensora da Pachamama, de Abya Yalae, de Sumak Kawsay, da minga e do ayllu,

\footnotetext{
3 "Pachatata como espaço-tempo masculino, diagrama do mundo atualizado, extensivo e, de certo modo, formal. Conjunção do mundo no repouso do extenso (apresentação do diferente, a "natureza naturada", de Espinosa), cujo movimento possível é interno à organização (as funcionalidades orgânicas e determinadas). Espaço do real atual (visível) e Tempo do perceptível (o campo do possível) e do intencional" (ANJOS, FEHLAUER, 2017, p. 109).
} 
Artigo | Política econômica no Pachamamismo do Buen Vivir: um estudo teórico (MORAES, Isaías Albertin de; MORAIS, Leandro Pereira)

fazendo uma severa crítica ao modernismo, ao neoliberalismo e ao nacionaldesenvolvimentismo. Os principais autores do Pachamamismo são: Viteri Gualinga (2002); Nina Pacari (2009); Luis Macas (2010); Blanca Chancosa (2010); Humberto Cholango (2011); Pablo Dávalos (2011); Milton Cáceres (2011); Atawallpa Oviedo (2011), entre outros.

Chancosa afirma:

[...] el sumak kawsay es una práctica social de los pueblos indígenas; es un proyecto societal indígena em permanente construcción, abierta a otros aportes, en el que quepan todas las entidades históricas y sociales comprometidas con la construcción de una nueva sociedad. El sumak kawsay no es un proceso cerrado, exclusivista; no puede serlo porque se sostiene en principios de inclusión y equidad (CHANCOSA, 2014, p. 209).

Os autores do Pachamamismo, em suma, acreditam que a harmonia com a natureza e o cosmo é algo primordial para garantia da vida de todos os seres humanos, da fauna, da flora, dos astros e da cultura, que são partes de uma mesma entidade divina superior possuidora de um movimento de vida: a Pachamama. Eles defendem, ademais, a minga, isto é, forma de trabalho coletivo, comunitário, obrigatório e sem remuneração monetária. Na minga a recompensa é o bem-estar social ao reunir toda a comunidade em um objetivo único. A minga é algo como um mutirão, ou seja, mobilizações coletivas para lograr um fim (colheita, capina da terra, construções de casas e/ou bens públicos, limpezas, etc.), baseando-se na ajuda mútua prestada gratuitamente. A minga ocorre no ayllu, que é a comunidade familiar. Essa, por sua vez, é baseada no compartilhamento de determinado território e não necessariamente em laços sanguíneos. O ayllu é uma comuna autogestionária que procura coletivamente alcançar o Sumak Kawsay. Ressalta-se que o Pachamamismo prefere utilizar somente o termo Sumak Kawsay e não Buen Vivir, pois afirma que esse conceito retirou a dimensão espiritual e mística que o Sumak Kawsay possui.

Macas (2010) resume esse sistema de ideias da seguinte forma:

El sistema comunitario se sustenta en los principios del randi-randi: la concepción y práctica de la vida en reciprocidad, la redistribución, principios que se manejan y están vigentes en nuestras comunidades. Se basa en la visión colectiva de los medios de producción, no existe la apropiación individual, la propiedad es comunitaria. El 
Artigo | Política econômica no Pachamamismo do Buen Vivir: um estudo teórico (MORAES, Isaías Albertin de; MORAIS, Leandro Pereira)

ruray, maki-maki, es la organización del trabajo comunitario, que se ha generalizado hoy por hoy en todos los pueblos. En Bolivia se dice la minka o el ayni. La organización del trabajo es así, absolutamente distinta a lo que nos han enseñado en la escuela, con mayor énfasis en la universidad. El ushay, es la organización social y política comunitaria, que es el poder de la organización, el sistema de organización. El yachay, los saberes y conocimientos colectivos, se sigue practicando en nuestras comunidades. Los saberes no son individuales sino colectivos, la transmisión de esos conocimientos va de generación en generación (MACAS, 2010, p. 14-15).

Para Cuelenaere e Rabasa (2012), o Pachamamismo é uma forma específica de movimento anti-sistêmico da América Latina visando desqualificar as categorias e as formas de pensamento do modernismo e do ocidente. Para Atilio Borón (2012), o Pachamamismo pode ser definido como uma política radical de conservação da natureza associada à revalorização da agricultura familiar e campesina. Na mesma linha segue Giraldo (2012), que considera o Pachamamismo um discurso crítico-radical inspirado pelas racionalidades das comunidades rurais contra os regimes modernos de verdade que estão levando a civilização a uma rota suicida. O movimento intenta, segundo Alcântara e Sampaio (2017), em desenvolver condições para promover um sistema socioeconômico harmônico do comunismo primitivo com economia equitativa e mutualista, pautando as diretrizes a partir da filosofia e do modo de vida dos povos originários da região.

Para Dávalos (2005), a teoria e o movimento do Pachamamismo são uma síntese da filosofia andina, do modo de vida dos povos originários da Abya Yala e das práticas de comunicação intercultural. O Pachamamismo traça críticas ao modelo de desenvolvimento ocidental e ao modernismo. Conforme Dávalos:

Cuando se constituye el Estado moderno, los indígenas, es decir, los habitantes originarios del continente denominado "América" serían excluidos de hecho y derecho de los sistemas de representación. De hecho, en los marcos constitucionales que se establecieron al inicio de las repúblicas latinoamericanas, la figura del ciudadano no contemplaba la diferencia y excluía de manera explícita a los indios de todo el sistema de representación, de todo el entramado institucional del Estado. Los indios, para el poder, estaban fuera de la política, fuera del Estado, fuera de la república, fuera del presente y de la historia. El orden que se construye los excluye de facto y de juris. Para ser ciudadano es necesario ser blanco-mestizo, es necesario tener rentas, es necesario saber leer y escribir. Y es una exclusión que se hizo desde la razón, que se justificó y legitimó desde ese entramado conceptual, teórico, axiológico y normativo dado por la modernidad (DÁVALOS, 2005, p. 25). 
Artigo | Política econômica no Pachamamismo do Buen Vivir: um estudo teórico (MORAES, Isaías Albertin de; MORAIS, Leandro Pereira)

O Pachamamismo defende, assim, que a ideia de liberalismo econômico ou nacional-desenvolvimentismo está associada na maneira moderna e eurocêntrica de se compreender o mundo. Essa visão foi imposta pelas relações coloniais e imperialistas entre as distintas sociedades ao longo do tempo. No cerne dos conceitos de liberalismo econômico ou de nacional-desenvolvimentismo, para o Pachamamismo, está a necessidade de querer imitar a organização econômica, política, social e seguir as rotas dos países centrais industrializados, capitalistas e liberais. Segundo Prada (2012), isso faz com que esses conceitos sejam limitados em razão de seguir as mesmas diretrizes que ocasionaram a crise capitalista estrutural da modernidade, ou seja, tentam explorar o produtivismo, o consumismo e o uso indiscriminado dos recursos naturais. 0 modernismo, o liberalismo econômico e o nacional-desenvolvimentismo são responsáveis pela atual situação do planeta, logo não são capazes de criar a solução. Seria preciso, dessa forma, resgatar saberes e práxis social dos povos originários de $A b y a$ Yala.

De acordo com Escobar (2012), autor que orbita entre a corrente IndigenistaPachamamista e Pós-desenvolvimentista-ecologista, o modernismo foi uma estratégia de dominação colonial e se coloca de forma autoritária sobre os saberes e os conhecimentos dos povos originários da América Latina. Esse processo criou condições históricas, econômicas e sociais de dominação e de destruição dos corpos, dos saberes e da memória dos nativos da comunidade de Abya Yala.

Segundo Belanger (2011), o Pachamamismo possui uma cosmovisão autônoma, ética, espiritual e é defensor de uma relatividade científica. A cosmovisão autônoma do Pachamamismo não é necessariamente, de acordo com Belanger (2011, p.183), "um modelo" ou "receita", mas um sistema de pensamentos, de éticas, de valores e de sensibilidades espirituais. Um sistema aberto a novas influências culturais, gerando uma cosmologia. Gualinga (2002) descreve essa cosmologia como:

En la cosmovisión de las sociedades indígenas, en la comprensión del sentido que tiene y debe tener la vida de las personas no existe el concepto de desarrollo. Es decir, no existe la concepción de un proceso lineal de la vida que establezca un estado anterior o posterior, a saber, de sub-desarrollo y desarrollo; dicotomía por los que deben transitar las personas para la consecución de bienestar, como ocurre en el mundo occidental. Tampoco existen conceptos de riqueza y pobreza determinado por la acumulación y 
Artigo | Política econômica no Pachamamismo do Buen Vivir: um estudo teórico (MORAES, Isaías Albertin de; MORAIS,

carencia de bienes materiales. [...] Por la diversidad de elementos a los que están condicionadas las acciones humanas que propician el 'alli káusai', como son el conocimiento, los códigos de conducta éticas y espirituales en la relación con el entorno, los valores humanos, la visión de futuro, entre otros, el concepto del alli káusai constituye una categoría central de la filosofía de vida de las sociedades indígenas. Visto así el alli káusai o sumac káusay constituye una categoria en permanente construcción (GUALINGA, 2002, p.01).

O Pachamamismo, para Hidalgo-Capitán (2012), tem a pretensão de recriar as condições harmônicas baseadas em um sistema socioeconômico de comunismo primitivo e mutualista em que supostamente vivia os povos originários da região. Dessa maneira, apresenta um preponderante discurso pré-moderno e contra a opressão da racionalidade, da secularidade e da segurança epistemológica-metodológica presentes no modernismo, considerado eurocêntrico e com valores imperialistas. O Pachamamismo reverencia a espiritualidade, a magia, o mito, a natureza sociocultural e estética na construção do saber e do conhecimento. Isso fica claro em Viteri Gualinga:

El conocimiento incluye además la esfera de lo trascendente o de lo espiritual. Allí se configura la visión indígena sobre el universo selva, en donde las distintas formas de vida son concebidas como seres análogos a las personas, guiadas y protegidas por grandes espiritus, con quienes el hombre está destinado a convivir en base al diálogo permanente. Dentro de esta visión, la selva y la tierra son estratos que unen los espacios físicos con lo intangible, lo material con lo espiritual, cuyo mediador constituye la persona savia (yachac en runa shimi). La práctica social de ésta visión sobre la vida y el cosmos, resulta fundamental en la dinámica de la construcción del Alli Káusai (GUALINGA, 2002, p.02).

Enquanto Hidalgo-Capitán (2012) acusa o Pachamamismo de uma visão prémoderna, Dávalos (2005, p.23) afirma que os povos originários da região são portadores de saberes e de racionalidades diferentes dos apregoadas pelo modernismo. Consequentemente, não é possível classificar essa racionalidade de "pré-moderna", de "tradicional", de "inocente" ou de "subdesenvolvida". A busca do Pachamamismo, para Dávalos (2005), é pela alteridade, isto é, o reconhecimento de outros saberes, de outras práticas e de outras formas de relacionamento dentro de uma sociedade complexa e com cosmovisões complementares. Por outro lado, Oviedo (2012) atribui que o Buen 
Artigo | Política econômica no Pachamamismo do Buen Vivir: um estudo teórico (MORAES, Isaías Albertin de; MORAIS, Leandro Pereira)

Vivir é pós-moderno enquanto o Pachamamismo é ancestral e pré-moderno sim. Esse debate, portanto, não está consolidado, pois há divergência dentro da própria corrente.

O Pachamamismo acusa os governos progressistas da América Latina e os setores das demais corretes do Buen Vivir (Socialista-Estadista e Pósdesenvolvimentista-ecologista) de persistirem em um desenvolvimentismo neoextrativista (MACAS, 2010; OVIEDO, 2011, 2012; DÁVALOS, 2005). Para o pensador da corrente Pós-desenvolvimentista-ecologista do Buen Vivir, Gudynas (2009), o neoextrativismo é caracterizado pelo centro dinâmico de acumulação de capital oriunda das exportações de recursos naturais. No entanto, há a construção de um "Estado compensador" que distribui socialmente os excedentes gerados no setor extrativista para grupos sociais anteriormente marginalizados no processo de desenvolvimento econômico.

Segundo Nunes (2018), a principal mudança entre o modelo neoextrativista atual de governos progressistas como a Bolívia de Evo Morales do período da ortodoxia convencional da década de 1990 refere-se à função do Estado. Se na ortodoxia convencional o foco é no papel do Estado como garantidor dos direitos de propriedade privada; no neoextrativismo, o Estado passa a ser protagonista na condução das atividades extrativistas, desempenhando atribuições como: regulação dos setores extrativos, nacionalização e promoção de empresas e priorização de políticas sociais e redistributivas.

Para o Pachamamismo, alguns setores do Buen Vivir e do desenvolvimentismo econômico consolidaram o modelo neoextrativista e continuam explorando os recursos naturais, produzindo relações sociais frágeis com valores liberais (LANDER, 2014). No entanto, autores das correntes Socialista-Estadista e Pós-desenvolvimentista-ecologista do Buen Vivir, como o próprio vice-presidente da República Plurinacional da Bolívia, Álvaro García Linera $(2010,2012,2017)$, defende o neoextrativismo no sentido de que é uma etapa necessária para proporcionar condições materiais, sociais, médicas e tecnológicas que possibilitariam o avanço para outras fases até alcançar um Socialismo Comunitário pautado no Sumak Kawsay. As fases são categorizadas em quatro pelo autor da corrente Socialista-Estadista, Gallego: 
La primera fase es de transición en términos de acumulación, en el sentido de dependencia de los bienes primarios para sostener la economía; no así, en términos de (re)distribución, considerada como el centro del cambio en este período, y en general como eje de la estrategia en su conjunto. A través de un proceso de sustitución selectiva de importaciones, impulso al sector ecoturístico comunitario, agroecológico y de inversión pública estratégica que fomente la productividad sistémica - con énfasis en la conectividad-, se sientan las bases para construir la industria nacional y producir cambios sustanciales en la matriz energética, motores de generación de riqueza en este período [...]. En la segunda fase, el peso relativo de la nueva industria nacional se incrementa frente a la de base primaria, y se busca consolidar un superávit energético, principalmente a través de la producción y consumo de energía limpia y bioenergía. En esta fase se apuntala la estrategia de generación de riqueza a través del ecoturismo comunitario y se busca que, desde el propio proceso productivo, se distribuya el excedente a través del reforzamiento de la economía popular, social y solidaria [...]. La tercera fase consolida una estrategia de diversificación y sustitución de exportaciones. Se espera que la industria nacional satisfaga la demanda interna y genere excedentes para exportación. Asimismo, la estrategia busca sustituir exportaciones por bienes con mayor valor agregado y no exclusivamente dependientes de procesos extractivos [...]. De la misma forma, en esta fase se consolida un sistema de seguridad social que permite acumular riqueza para la inversión pública que requiera el país. En la cuarta fase, la estrategia tiene como objetivo el despegue de los bioservicios y su aplicación tecnológica. Se busca que el tamaño relativo de este tipo de servicios - principalmente de bioconocimiento-y de los servicios turísticos tenga un peso superior al generado por el sector primario. Los servicios de conocimiento que se auspicien estarán vinculados con las industrias nacientes que se fomentaron desde la primera fase (GALLEGOS, 2010, p. 1920 , grifo no original).

O Pachamamismo não compartilha dessa visão apresentada por Linera e Gallegos, representantes da corrente Socialista-Estadista do Buen Vivir. De acordo com Dávalos (2008) e Macas (2010), nem o pensamento econômico keynesiano nem o marxista e tampouco o liberal conseguem responder para as crises econômicas da América Latina. Para os Indigenista-Pachamamista é necessário viabilizar formas não etapistas ou dualistas de desenvolvimento e de conhecimento. O sujeito-histórico capaz de proporcionar isso são os pachamámicos considerados os indígenas, os afrodescendentes e aqueles que continuam tendo alguma relação afetivo-simbólica com o território e o lugar. Segundo Dávalos: 
El discurso económico moderno ha llegado incluso al autismo absoluto: el pensamiento keynesiano que alguna vez abrió las posibilidades para comprender analíticamente la intervención del Estado en la economía, no existe más. En efecto, los modernos textos de economía ni siquiera mencionan el aporte de Keynes y su invisibilización epistemológica es casi total. La adscripción a la idea de los mercados como únicos reguladores sociales, ha acotado de tal manera al discurso de la economía, que se ha convertido en un dispositivo teórico legitimante de las corporaciones. [ ...] Mientras que la teoría económica vigente adscribe al paradigma cartesiano del hombre como "amo y señor de la naturaleza", y comprende a la naturaleza desde una ámbito externo a la historia humana (un concepto que incluso es subyacente al marxismo), el sumak kawsay (buen vivir) incorpora a la naturaleza en la historia. Se trata de un cambio fundamental en la episteme moderna, porque si de algo se jactaba el pensamiento moderno es, precisamente, de la expulsión que había logrado de la naturaleza de la historia (DÁVALOS, 2008, p. s/n).

Percebe-se que o arcabouço filosófico e o discurso de manifesto do Pachamamismo estão de certa maneira estruturados. A teoria e o movimento, todavia, não apresentam uma política econômica original e inovadora. Para Stefanoni (2011a, 2011b), o Pachamamismo é somente um discurso romântico e vazio que faz sucesso exclusivamente em ciclos de uma crescente esquerda New Age global de classe média, anti-moderna e anti-ciência. Segundo Stefanoni (2011b, 2011c), o Pachamamismo não apresenta nada concreto de como construir um novo modelo de desenvolvimento econômico e tampouco aponta um caminho para superar o capitalismo dependente, 0 rentismo e o neoextrativismo, permitindo, assim, a construção de um novo pacto social.

De acordo com Stefanoni (2011b, 2011c), o Pachamamismo possui uma escassa capacidade de refletir as etnicidades realmente existentes, pois se ocupa de limitações políticas indentitárias e pouco preocupadas com o processo de correção do sistema econômico vigente.

[...] cuando hablé de pachamamismo no me referia ni me refiero a los indígenas, ni a una corrente ideológica o intelectual definida, sino a un discurso difuso y vacío (proveniente de algunos, no todos, decoloniales, subalternistas y autonomistas, además de adherentes a otras corrientes postmodernas) sobre la Pachamama y uma supuesta epistemologia antimoderna, que construye uma cosmovisión andina de salón, y 
Artigo | Política econômica no Pachamamismo do Buen Vivir: um estudo teórico (MORAES, Isaías Albertin de; MORAIS, Leandro Pereira)

ventrilocuea a los indígenas realmente existentes de quienes se atibuye su representación (STEFANONI , 2011c, p. 186).

Stefanoni (2011b, 2011c) acusa o Pachamamismo de inviabilizar o debate sério sobre desenvolvimento econômico, de justiça social e de mudanças climáticas. Isso ocorre, pois, o movimento Pachamámico fica preso em um discurso esotérico-abstrato e utópico. Para Stefanoni (2011b, 2011c), o Pachamamismo não reconhece que os avanços econômico-sociais tanto na Bolívia quanto no Equador se devem muito mais as políticas econômicas keynesiana-desenvolvimentistas - com forte aporte nacionalpopular, visando a construção de uma socialdemocracia - do que a um discurso estéticoreligioso, uma quase "neolíngua", capaz de ampliar por meio de construções vazias até o infinito o hiato entre a retórica e a realidade, debilitando, então, as reais energias transformadoras de sociedade.

As argumentações de Stefanoni (2011a, 2011b, 2011c) repercutiram significativamente no meio acadêmico e na imprensa dos países andinos, lançando-o como principal crítico do Pachamamismo na atualidade. Em certos pontos, Stefanoni (2011a, 2011b, 2011c) é certeiro, como as limitações da política indentitária como agente de superação do subdesenvolvimento econômico e da dependência, o excesso de romantismo rousseauniano (crença no bom selvagem, por exemplo), a forte prevalência da estética nos autores e nos discursos da corrente, especialmente por uma esquerda consumidora de movimentos espiritualistas como Zen, New Age ou Sagrados; e o não reconhecimento dos méritos das políticas econômicas keynesianadesenvolvimentistas nos avanços sociais tanto na Bolívia quanto no Equador.

Stefanoni (2011a, 2011b, 2011c), porém, pesa na crítica de que o Pachamamismo inviabiliza o avanço do debate, porquanto a corrente levanta tópicos essenciais como: a diversidade de organização social, a cosmovisão, a muldimensionalidade dos saberes, a plurinacionalidade e a interculturalidade, além de ser uma plataforma que dá espaço para o protagonismo de autores dos povos originários de Abya Yala. 
Artigo | Política econômica no Pachamamismo do Buen Vivir: um estudo teórico (MORAES, Isaías Albertin de; MORAIS, Leandro Pereira)

\section{Considerações finais}

O presente artigo teve como objetivo investigar a corrente teórica do Buen Vivir denominada de Pachamamismo. A pergunta levantada pela pesquisa é: há uma proposta de política econômica própria do Pachamamismo? A hipótese é de que o Pachamamismo não possui um arcabouço de política econômica original e própria, permanecendo no âmbito do culturalismo e da filosofia social. Para procurar responder a perguntar proposta e testar a hipótese elencada, o artigo se dividiu em duas partes. Procurou-se apresentar, na primeira seção, o conceito de Buen Vivir e como ele está sendo construído na América Latina. Pode-se notar que o Buen Vivir é um campo semântico mais complexo e amplo do que o Pachamamismo. Na verdade, a corrente Indigenista-Pachamamista, conhecida de Pachamamismo, é uma das vertentes do movimento do Buen Vivir. Na segunda seção, a pesquisa focou somente na abordagem sistemática por meio da avaliação crítica dos dados bibliográficos voltados para a construção política-social-econômica e filosófica do Pachamamismo. Ao fazer a análise das referências bibliográficas pode-se validar a hipótese elencada pela pesquisa, isto é, o Pachamamismo não possui um arcabouço de política econômica original e própria.

Em relação à economia, o Pachamamismo tenta resgatar a práxis social dos povos originários como a minga e o ayllu. Os autores buscam criar um sistema que amplie a justiça socioeconômica, pautando as relações econômicas na solidariedade, no comunitarismo e no bem-estar em vez do mecanicismo, do progressismo, do utilitarismo, da competição, da meritocracia e da acumulação de capital via lucro. Ainda assim, neste campo, o discurso se mantém abstrato e simbólico, menosprezando as políticas macroeconômicas de controle dos cinco preços da macroeconomia (a taxa de câmbio, a taxa de juros, a taxa de salários, a taxa de inflação e a taxa de lucro), as políticas de Previdência Social e as políticas de ciência, inovação e tecnologia, por exemplo.

O fato de o Pachamamismo não possuir uma teoria e/ou propostas econômicas concretas para viabilizar a superação do neoextrativismo na América Latina, ou até mesmo do próprio sistema capitalista, não marginaliza sua importância como movimento. Uma vez que o Pachamamismo manifesta uma filosofia social consolidada, 
Artigo | Política econômica no Pachamamismo do Buen Vivir: um estudo teórico (MORAES, Isaías Albertin de; MORAIS, Leandro Pereira)

uma agenda política relevante, um programa pedagógico válido, uma estética e um quadro legal que definem perspectivas não ocidentais para refletir sobre a interseção entre natureza, civilização e cultura na América Latina. A resistência das comunidades camponesas e indígenas na América Latina contra formas brutais e violentas de acumulação primitiva permanente de capital é louvável e fundamental.

Por outro lado, é importante que o movimento do Pachamamismo reconheça seus limites e atuações de possível condutor das transformações mais amplas da sociedade. A manutenção de um discurso abstrato, estético, simbólico, customizado e segmentado, enfatizando a alteridade e o moralismo anti-capitalista pode isolar 0 movimento e ofuscar algumas de suas demandas legitimas, por exemplo, a questão de tratar a "Mãe Terra" como sujeito de direito ou a sua defesa por uma economia comunitária e solidária. Outro ponto importante é que ao focar suas críticas aos modernistas e aos desenvolvimentistas, o Pachamamismo abre outra frente de ataques contra esse grupo de progressistas, que já enfrenta um debate profundo e amplo com os neoliberais. Isso faz com que os governos progressistas tenham sua sustentação social-política fragilizada.

Por fim, o Pachamamismo precisa superar o teatro simbólico discursivo e orientado para questões indentitárias e entender que se pretende ter sua força política ampliada e executada necessita ter um projeto político voltado para infraestrutura econômica de unificação social. O discurso anti-moderno e anti-ciência pode abrir espaço para o obscurantismo e para crença de que tudo não passa de um conjunto de meras hipóteses ou especulações, criando um vasto número de "verdades". É mais viável lutar por um desenvolvimento econômico-social-político ético e multidimensional capaz de englobar uma revitalizada filosofia e cultura dos povos originais de Abya Yala do que ficar anelando uma regressão utópica ou simbólica para uma Era pré-moderna e pré-pessoal anterior a invasão europeia na região.

\section{Referências}

ACOSTA, A. El Buen Vivir en el camino del post-desarrollo: una lectura desde la Constitución de Montecristi. Policy Paper, n. 9, 05-43, 2010. Disponível em: 
Artigo | Política econômica no Pachamamismo do Buen Vivir: um estudo teórico (MORAES, Isaías Albertin de; MORAIS, Leandro Pereira)

https://www.fuhem.es/media/cdv/file/biblioteca/Analisis/Buen vivir/Buen vivir posd esarrollo A. Acosta.pdf. Acesso em 10 de mai. 2019.

ACOSTA, A. O Bem Viver: uma oportunidade para imaginar outros mundos. São Paulo: Autonomia Literária: Elefante, 2016.

ALCÂNTARA, L. C. S.; SAMPAIO, C.A.C. Bem Viver: uma perspectiva (des)colonial das comunidades indígenas. Rev. Rupturas 7(2), Costa Rica, 1-31, 2017. Disponível em: https://www.scielo.sa.cr/pdf/rup/v7n2/2215-2989-rup-7-02-00001.pdf. Acesso em 05 mar. 2019.

ANJOS, J. C. G.; FEHLAUR, T. J. Para além do "pachamamismo": Pachamama e Sumak Kawsay como potência cosmopolítica andina. Tellus, Campo Grande, MS, ano 17, n. 32, 103-118, 2017. Disponível em: http://www.tellus.ucdb.br/index.php/ tellus/article/view/442. Acesso em 04. De mar. 2019.

BELANGER, M. Carta a Pablo Stefanoni sobre el Pachamamismo. Tierra Socialista. Ano 2, no 2, 174-185, 2011.

BOFF, L. A grande transformação: na economia, na política e na ecologia. Petrópolis: Vozes, 2014.

BOLÍVIA. Constitución Política del Estado (CPE), 7-Febrero, 2009.

BORÓN, A. América Latina en la geopolítica del imperialismo. Buenos Aires: Luxemburg, 2012.

BRESSER-PEREIRA, L. C. Em busca do Desenvolvimento Perdido: um projeto novo-desenvolvimentista para o Brasil. São Paulo: FGV Editora, 2018.

CÁCERES, M. V. Interculturalidad y sostenibilidad. Conceptualidad y proyecciones. Quito: El Cuidado, 2011.

CASTELO, R. O Social-Liberalismo: Auge e Crise na supremacia burguesa na era neoliberal. São Paulo: Expressão Popular, 2013.

CHANCOSA, B. El Sumak Kawsay desde la visión de la mujer, América Latina en Movimiento. Quito: ALAI, 453, 6-9, 2010.

CHANCOSA, B. El Sumak Kawsay desde la visión de la mujer. In: HIDALGOCAPITÁN, A.; GARCÍA, A.G; GUAZA, N.D. (Org.) Antología del pensamiento indigenista ecuatoriano sobre Sumak Kawsay. Huelva: CIM/FIUCUHU/Pydlos, 2014.

CHOLANGO, H. Conaie. 25 años construyendo el estado plurinacional para el Buen Vivir. Quito: La Línea de Fuego, 2011.

CHOQUEHUANCA, C. Hacia la reconstrucción del Vivir Bien. In: América Latina en Movimiento. Sumak Kawsay: Recuperar el sentido de la vida. Quito: ALAI, 2010.

CORTEZ, D. La construcción sociais del "Buen Vivir" (Sumak Kawsay) en Ecuador. Aportes Andinos 28, 1-23. 2011. Disponível em: http://www.socioeco.org/bdf fichedocument-3877 pt.html. Acesso em 10 de mai. 2019.

CUELENAERE, L., RABASA, J. Pachamamismo, o las ficciones de (la ausencia de)

voz. Cuadernos de literatura no32, 184-185, 2012. Disponível em: https://revistas.javeriana.edu.co/index.php/cualit/article/view/4067/3069. Acesso em 10 de mar. 2019. 
Artigo | Política econômica no Pachamamismo do Buen Vivir: um estudo teórico (MORAES, Isaías Albertin de; MORAIS, Leandro Pereira)

DÁVALOS, P. Movimientos indígenas en América Latina: el derecho a la palavra. Buenos Aires: Clacso Libros, Colección Grupos de Trabajo, 2005.

DÁVALOS, P. Reflexiones sobre el Sumak Kawsay (el Buen Vivir) y las teorías del desarrollo. Quito: ALAI, 2008.

DÁVALOS, P. Sumak Kawsay (La Vida en Plenitud). In: Cantalapiedra, Álvarez S. (Org.). Convivir para perdurar. Conflictos ecosociales y sabidurías ecológicas. Madrid: Icaria, 2011.

DOWBOR, L. A Era do Capital Improdutivo. São Paulo: Outras Palavras, 2017.

EQUADOR. Constitución de la República del Ecuador, 2008.

ESCOBAR, A.¿Pachamámicos contra Modernicos? Tierra Socialista. Ano 2, no 2,198-207, 2011.

ESCOBAR, A. Latin America at a Crossroads: Alternative Modernizations, Postliberalism, or Post-development? Cultural Studies, v. 24, n. 1, 1-65, 2010.

ESCOBAR, A. O lugar da natureza e a natureza do lugar: globalização ou pósdesenvolvimento? In: LANDER, E. (Org.). La Colonialidad del saber: eurocentrismo y ciencias sociales. Perspectivas latinoamericanas. Buenos Aires: Clacso Libros y Unesco, Unidad Regional de Ciencias Sociales y Humanas para América Latina y el Caribe, 2005.

ESCOBAR, A. Una minga para El posdesarrollo. Signo y Pensamiento 58 Puntos de vista, v. XXX, 306-312, 2011. Disponível em: http://revistas.javeriana.edu.co/index.php/signoypensamiento/article/view/2501.

Acesso em 14 de mar. 2019

ESTERMANN, J. Ecosofía andina: un paradigma alternativo de convivência cósmica y de vivir bien. FAIA, v. II, n. IX-X, 1-21, 2013. Disponível em: https://dialnet.unirioja.es/servlet/articulo?codigo=4714294. Acesso em 17 de mar. 2019.

ESTERMANN, J. Filosofia andina. Quito: Abya-Yala, 1998.

ESTERMANN, J. Vivir bien como utopia política. La concepción andina del vivir bien (suma qamaña/allin kawsay) y su aplicación en el socialismo democrático en Bolívia, 2012.

GALLEGOS, R. Los Nuevos Retos de America Latina. Socialismo del Sumak Kawsay o biosocialismo republicano. Senplades, 55-74, 2010.

GARCÍA LINERA, Á. El pueblo boliviano vive la mayor revolución social. Entrevista de Luis Hernández Navarro de Diario La Jornada de México, 2012. Disponível em: http://www.vicepresidencia.gob.bo/IMG/pdf/entrevista la jornada de mexico.pdf. Acesso em 10 de mai. 2019.

GARCÍA LINERA, Á. Una Vez Más Sobre el Llamado Extractivismo. Nodal: Noticias de America Latina y el Caribe, 2017.

GARCÍA LINERA, Á. El Estado en transición. Bloque de poder y punto de bifurcación. Casa de las Américas, La Habana, n. 259/260, 90-110, 2010. Dispónível em: http://bibliotecavirtual.clacso.org.ar/ar/libros/coedicion/linera/7.4.pdf. Acesso em 20 de mai. 2019. 
GIRALDO, O. F. El discurso moderno frente al "pachamamismo": La metáfora de la naturaleza como recurso y el de la Tierra como madre. Santiago: Polis, Revista de la Universidad Bolivariana, Volumen 11, no 33, 219-233, 2012. Disponível em: https://journals.openedition.org/polis/8502. Acesso em 14 de mar. 2019.

GUALINGA, C. V. Visión indígena del desarrollo en la Amazonía. Santiago: Polis. Revista Académica Universidad Bolivariana, 3,01-06, 2002. Disponível em: https://journals.openedition.org/polis/7678. Acesso em 20 de mai. 2019.

GUDYNAS, E. Vivir Buen: amanhã de hoje. Desenvolvimento, 54 (4), 441-447, 2011.

GUDYNAS, E. Diez tesis urgentes sobre el nuevo extractivismo. Contextos y demandas bajo el progresismo sudamericano actual. In: Extractivismo, política y sociedad, Quito-Montevideo: CAAP y CLAES, 2009.

GUILLEMOT, Y. Para leer Qhapaq Kuna: un nuevo paradigma? In: LAJO, J. Qhapaq Ñan: la ruta inka de sabiduría. Quito: Editorial Abya Yala, 2006.

HARVEY, D. O Neoliberalismo: história e implicações. São Paulo: Edições Loyola, 2008.

HIDALGO-CAPITÁN, L. A. El Buen Vivir: la (re) creación del pensamento del PYDLOS". Universidad de Cuenca, 2012.

JIMÉNEZ, R. Recovering and values other ethical pillars. Buen Vivir". Forum for a New World Governance, 2011.

KATZ, C. Neoliberalismo, Neodesenvolvimentismo, Socialismo. São Paulo: Expressão Popular, 2016.

LAJO, J. Qhapaq Ñan: aa ruta inka de sabiduría. Quito: Editorial Abya Yala, 2006.

LANDER, E. The Modern History of Venezuela and the Need for a Post-Oil Economy. The Real News Network, 2014.

LEÓN, M. El "buen vivir": objetivo y camino para otro modelo. La Tendencia, Quito, 2008.

MACAS, A., L. Sumak Kawsay. La vida en plenitude. In: América Latina en Movimiento. Sumak Kawsay: Recuperar el sentido de la vida. Quito: ALAI, 2010.

MALISKA, M.A.; MOREIRA, P.D. O Caso Vilcabamba e El Buen Vivir na Constituição do Equador de 2008: pluralismo jurídico e um novo paradigma ecocêntrico. Florianópolis: Seqüência, n. 77, 149-176, 2017. Disponível em: http://www.scielo.br/scielo.php?pid=S217770552017000300149\&script=sci abstract \&tlng=pt. Acesso em 23 de mar. 2019.

MAMANI, F. Buen Vivir/Vivir Bien. Filosofia, políticas, estratégias y experiências regionales andinas. Coordinadora Andina de Organizaciones Indígenas CAOI. Lima, 2010.

MARTINS, C.E. Globalização, Dependência e Neoliberalismo na América Latina. São Paulo: Boitempo, 2011.

MEDINA, J. Suma Qamaña. La comprensión indígena de la Buena Vida. La Paz: PADEP/GTZ, 2008. 
Artigo | Política econômica no Pachamamismo do Buen Vivir: um estudo teórico (MORAES, Isaías Albertin de; MORAIS, Leandro Pereira)

MIGNOLO, W. El pensamiento dês-colonial, desprendimiento y apertura: um manifesto. Tristes Trópicos. 2005.

NUNES, T. G. A. O extrativismo progressista na América do Sul: uma análise a partir da experiência boliviana. Rev. Cadernos de Campo, Araraquara, n. 24, 63-84, 2018.

OVIEDO A. F. Qué es el Sumakawsay. Más allá del socialismo y el capitalismo. Quito: Sumak Ediciones, 2011.

PACARI, N. V. Naturaleza y territorio desde la mirada de los pueblos indígenas. In: ACOSTAS, A. y MARTíNEZ. E y. (Org.) Derechos de la Naturaleza. El futuro es ahora. Quito: Ediciones Abya-Yala, 2009.

PRADA, A. R. Más allá del capitalismo y la modernidade. Bolívia:Katari, 2012.

RADCLIFFE, S. A. Development for a postneoliberal era? Sumak kawsay, living well and the limits to decolonisation in Ecuador. Geoforum, 43 (2), 240-249, 2012. Disponível

em: http://www.cedla.uva.nl/30 courses/pdf/Development for a postneoliberal era.pdf. Acesso em 14 de mai. 2019.

STEFANONI, P. ¿Adónde nos lleva el Pachamamismo? Tierra Socialista. Ano 2, no 2, 166-167, 2011a.

STEFANONI, P. Indianismo y pachamamismo. Tierra Socialista. Ano 2, no 2, 167169, 2011b.

STEFANONI, P. Pachamamismo ventrilocuo. Tierra Socialista. Ano 2, no 2, 185$189,2011 \mathrm{c}$.

THOMSON, B. Pachakuti: perspectivas indígenas, buen vivir, kawsay Sumaq e decrescimento. Desenvolvimento, 54 (4), 448-454, 2011.

TORREZ, M. Estructura y proceso de desarrollo del Qamaña. Espacio de bienestar. Pacha, 6, 45-67, 2001.

VANHULST, J. BELING, A. Buen vivir: Emergent discourse within or beyond sustainable development? Elsevier, Ecological Economics 101: 54-63, 2014. Disponível em: http://isiarticles.com/bundles/Article/pre/pdf/44111.pdf. Acesso em 26 de mar. 2019.

WALSH, C. Desenvolvimento como Buen Vivir: Acordos institucionais e (de) envolvimentos coloniais. Desenvolvimento, 53 (1), 15-21, 2010.

YAMPARA, H. S. Viaje del Jaqi a la Qamaña. El hombre en el Vivir Bien. In: MEDINA, J. Suma Qamaña. La comprensión indígena de la Buena Vida. La Paz: PADEP/GTZ, 2008. 